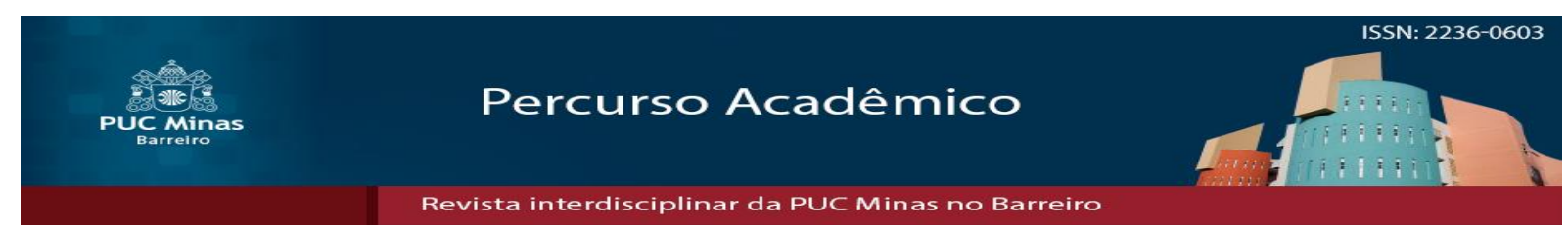

\title{
Liderança e Gestão: A evolução e a completude dos papéis
}

\section{Leadership and Management: The evolution and completeness of its roles}

\author{
Roseli Chaves ${ }^{1}$ \\ Ricardo Vinícius Dumbá de Macedo ${ }^{2}$ \\ Mario Teixeira Reis Neto ${ }^{3}$ \\ Luiz Cláudio de $\mathrm{Lima}^{4}$
}

\section{RESUMO}

Gestão e liderança são palavras que se confundem - é comum tratá-las como sinônimos, assim como os responsáveis por exercer tais papéis - gestor e líder. Este artigo traz uma revisão literária da relação entre ambos e dos dois conceitos distintos, trazendo diversas visões, de diferentes épocas e ambientes, sobre o assunto. São vistas variadas definições e consolidação de algumas delas, por afinidade, facilitando o entendimento teórico e sua aplicação prática. Tida esta visão dos conceitos, destaca-se as lacunas encontradas no tema, sugere-se a realização de estudos complementares, e conclui-se haver a existência de uma distinção importante entre os papéis, que deve ser levada em conta na aplicação prática da função.

Palavras-chave: Liderança, gestão, funções, equipes.

\begin{abstract}
Management and leadership are words that confuses themselves - that is usual to use them as synonyms. The same happens with the responsible for playing these roles - manager and leader. This paper brings a literature review of the relationship between both roles and of the concepts, bringing several views, from different times and environments, about the theme. Several definitions are seen, and some of them are consolidated, by affinity, making easier the theorical understanding and its practical application. Had this concepts view, the founded gaps on the theme are highlighted, complimentary
\end{abstract}

\footnotetext{
Artigo recebido em 13 de janeiro de 2020 e aprovado em 13 de agosto de 2020

${ }^{1}$ Mestranda em Administração pela Fundação Mineira de Educação e Cultura (FUMEC), Especialização em Gestão Estratégica de Pessoas pela Universidade Federal de Minas Gerais (UFMG) e Graduação em Ciências Contábeis Pontifícia Universidade Católica de Minas Gerais (PUC MG), Brasil. E-mail: chavesrosinha@hotmail.com

${ }^{2}$ Especialização em Gestão Estratégica da Logística e Produção pelo Centro Universitário de Belo Horizonte, possui graduação em Administração pelo Centro Universitário Newton Paiva. Atualmente é Gerente de Operações da Biomedical Prod. Científicos Médicos e Hospitalares. Brasil. E-mail: rvdmacedo@gmail.com

${ }^{3}$ Doutorado em Administração pela (UFMG), mestrado em Administração pela Universidade Federal do Rio de Janeiro (UFRJ), possui graduação em Engenharia Elétrica pela(PUCMG). Atualmente é professor do Programa de Doutorado e Mestrado em Administração da Universidade (FUMEC). Brasil. E-mail: reisnetomario@gmail.com

${ }^{4}$ PhD em Administração pela Universidade FUMEC, Mestre em Engenharia da Produção pela Universidade Federal de Santa Catarina, Graduado em Administração pela Universidade FUMEC, Especialista em Gestão de Recursos Humanos e Consultoria Organizacional pela Faculdade de Ciências Gerenciais da Una. Atualmente é Consultor Organizacional e Professor Titular da Universidade FUMEC. Brasil. E-mail: Icl@fumec.br
} 
studies are suggested, and also we conclude the existence of an important distinction between the roles, which should be taken in account on the practical application of the function.

Key words: Leadership, management, functions, teams

\section{INTRODUÇÃ̃O}

Com a chegada da Revolução 4.0, o crescimento tecnológico, a era do conhecimento, a escassez de mão de obra qualificada intensificou e tornou se necessário o entendimento do papel da gestão e da liderança como funções complementares, sendo a liderança um diferencial competitivo nas organizações.

Entre os autores do referencial teórico, encontram-se vários que distinguem bem o papel do gestor e do líder, mas também outros que falam sobre a completude destes papéis para que seja uma liderança de alto impacto. Algumas competências são citadas como prioridade para o desempenho da gestão e da liderança. O CHA é conhecido como conhecimento (é o saber: dominar a atividade, negócio), habilidade (aplicar e conseguir resultados com a habilidade que possui) e atitude (querer fazer, ser proativo). Para Gomes e Almeida (2002; p. 12-13): “tomar decisões complexas é, de modo geral, uma das mais difíceis tarefas enfrentadas individualmente ou por grupos de indivíduos, pois quase sempre tais decisões devem atender a múltiplos objetivos, e frequentemente seus impactos não podem ser corretamente identificados". Cada gestor tomará decisões de acordo com as suas crenças, valores e experiência. A empresa precisa definir qual estilo ou abordagem de liderança se adequa a sua cultura, e ter um gerente com competências de gestão e liderança que atenda as necessidades da equipe e da empresa. O gestor/líder precisa atentar para a maturidade da sua equipe e o estilo necessário de liderança ao qual eles precisam e se adequar. O líder, motiva, empodera, inspira os funcionários a entenderem a necessidade da mudança e adotarem como seus objetivos. Mas de nada adiantará se o líder não entender e operar o negócio, não conseguir focar nos processos e atender as necessidades da organização. Segundo Rothmann (2009), administrar a visão e o propósito é um dos grandes desafios com os quais se deparam os líderes. Os líderes precisam de determinadas habilidades para chegar a isso com sucesso e para criar confiança em sua capacidade de liderar.

São várias informações sobre as diferenças dos papéis, mas o mais importante é que os dois papéis podem ser complementares, pois o gestor, além de administrar, controlar, planejar e executar o planejamento estratégico, precisa estar ligado às pessoas, porque com o apoio destas, a organização alcança seu objetivo. 
O artigo se justifica pela sua relevância, pela liderança ser um diferencial competitivo nas organizações, sendo que esta pode influenciar positivamente ou negativamente seus funcionários criando vários impactos no clima organizacional. As pessoas precisam acompanhar as mudanças no ambiente interno e externo para continuarem atendendo as necessidades da organização.

A metodologia utilizada foi uma pesquisa bibliográfica, com o estudo e análise de conceitos de vários autores clássicos e contemporâneos com objetivo de demonstrar a importância da distinção e da completude dos papéis da gestão e da liderança.

De acordo com Vergara (1999), a liderança precisa trabalhar em ambientes ambíguos, cenários turbulentos, e que possuem competência técnica e comportamental, que tenham habilidades múltiplas, com valores e ética e saibam lidar com estas situações.

Segundo Maximiano (2000, p.343) o estilo de liderança é a forma como a liderança age com seus funcionários, em grupo, ou pessoa por pessoa, podendo ser democrático, autocrático ou liberal, e segundo Adair (1992) o estilo laissez-faire que se assemelha ao liberal.

Drucker (2006) caracteriza estes três tipos de liderança elencados no quadro abaixo.

\section{Tipos de Liderança}




\section{Quadro 1: Estilos de Liderança}

\begin{tabular}{|c|c|c|}
\hline Autocrático & Democrático & Liberal (Laissez-Faire) \\
\hline $\begin{array}{l}\text { Apenas o líder fixa as diretrizes, } \\
\text { sem qualquer participação do } \\
\text { grupo. }\end{array}$ & $\begin{array}{l}\text { O líder é dominador e é "pessoal" } \\
\text { nos elogios e nas críticas ao } \\
\text { trabalho de cada membro. }\end{array}$ & $\begin{array}{l}\text { Há liberdade completa para as } \\
\text { decisões grupais ou individuais, } \\
\text { com participação mínima do } \\
\text { líder. }\end{array}$ \\
\hline $\begin{array}{l}\mathrm{O} \text { líder determina as } \\
\text { providencias e as técnicas para a } \\
\text { execução das tarefas, cada uma } \\
\text { por vez, na medida em que se } \\
\text { tornam necessárias e de modo } \\
\text { imprevisível para o grupo. }\end{array}$ & $\begin{array}{l}\text { O próprio grupo esboça as } \\
\text { providencias e as técnicas para } \\
\text { atingir o alvo, solicitando } \\
\text { aconselhamento técnico ao líder } \\
\text { quando necessário, passando este } \\
\text { a sugerir duas ou mais } \\
\text { alternativas para o grupo } \\
\text { escolher. As tarefas ganham nova } \\
\text { perspectivas com os debates. }\end{array}$ & $\begin{array}{l}\text { A participação do líder no debate } \\
\text { apenas material variados ao } \\
\text { grupo, esclarecendo que poderia } \\
\text { fornecer informações desde que } \\
\text { as pedissem. }\end{array}$ \\
\hline $\begin{array}{l}\text { O líder determina qual a tarefa } \\
\text { que cada um deve executar e } \\
\text { qual o seu companheiro de } \\
\text { trabalho. }\end{array}$ & $\begin{array}{l}\text { A divisão das tarefas fica a } \\
\text { critério do próprio grupo e cada } \\
\text { membro tem liberdade de } \\
\text { escolher os seus companheiros de } \\
\text { trabalho. }\end{array}$ & $\begin{array}{l}\text { Tanto a divisão das tarefas, como } \\
\text { a escolha dos companheiros, fica } \\
\text { totalmente a cargo do grupo. } \\
\text { Absoluta falta de participação do } \\
\text { líder. }\end{array}$ \\
\hline $\begin{array}{l}\text { O líder é dominador e é } \\
\text { "pessoal" nos elogios e nas } \\
\text { críticas ao trabalho de cada } \\
\text { membro. }\end{array}$ & $\begin{array}{l}\text { O líder procura ser um membro } \\
\text { normal do grupo, em espírito, } \\
\text { sem encarregar-se muito de } \\
\text { tarefas. O líder é "objetivo" e } \\
\text { limita-se aos "fatos" em suas } \\
\text { críticas e elogios. }\end{array}$ & $\begin{array}{l}\text { O líder não faz nenhuma } \\
\text { tentativa de avaliar ou regular o } \\
\text { curso dos acontecimentos. O } \\
\text { líder somente faz comentários } \\
\text { irregulares sobre as atividades } \\
\text { dos membros quando } \\
\text { perguntado. }\end{array}$ \\
\hline
\end{tabular}

Fonte: Drucker (2006). Adaptado pelo autor: Alonso Luiz Pereira (2014).

Quanto às funções de líder e gestor, o artigo busca, essencialmente, entender a diferença entre eles, se é que ela existe, e ver como cada autor as tratas, destacando as divergências e a completude dos papéis. Com isto, pretende-se simplificar os conceitos, contribuindo para um melhor entendimento e aplicação do tema em ambientes organizacionais por aqueles que desempenham estas funções. Busca-se, ao analisar especificamente o conceito de liderança, uma expurgação destes papeis que, porventura, sejam de responsabilidade do gestor (da atribuição do cargo).

\section{CONCEITUANDO GESTÃO E LIDERANÇA}

\subsection{Liderança e Gestão como conceitos relacionados}

Kotter (1990) afirma que liderança e gestão são dois sistemas distintos e complementares, cada um com sua função e características. Num ambiente de negócios cada vez mais complexo e volátil, ambos são necessários para o sucesso.

O autor ainda destaca que a liderança é diferente da gestão, mas não pelo que a maioria pensa. Segundo ele, a liderança não é mística e não tem a ver com carisma, por 
exemplo - e não vem, necessariamente, como um substituto para a gestão. "A liderança complementa a gestão; ela não a substitui”" (Kotter, 1990, p. 103).

Ainda segundo Kotter (1990), liderança e gestão envolvem decidir o que tem que ser feito, criar redes de relacionamento para agir conforme planejado, e tentar garantir que as pessoas cumpram suas obrigações no trabalho - mas cada um os faz à sua maneira.

Seguindo a obra mencionada, Rego e Cunha (2007) afirmam que gestão e liderança são processos distintos. Os autores defendem que ambos são necessários quando se quer atingir altos níveis de eficácia e eficiência - dependendo da exigência das funções desempenhadas na organização, os papeis de líder ou de gestor podem ser demandados.

Borges e Mendes (2014), em estudo de caso realizado na Polícia Portuguesa, visando entender as competências do gestor e do líder, afirmam que a gestão e a liderança são fatores distintos, mas que contribuem, ambos, para o sucesso da missão organizacional. A gestão é fundamental para a administração e planejamentos diários, e a liderança exerce papel importante no estímulo à inovação, criatividade e relações interpessoais. Um achado adicional da pesquisa é que a gestão e a liderança, apesar da distinção, são passíveis de serem integradas e desenvolvidas por uma só pessoa, pois existem pontos de interseção consideráveis entre os conceitos.

Para Sharma (2013), liderança e gestão devem andar de mãos dadas. Elas não se tratam da mesma coisa, porém estão necessariamente ligadas e são complementares uma à outra. Alegam que qualquer esforço para separar os dois conceitos é suscetível de causar mais problemas do que existem, e que já se gastou-se muito tempo delineando as diferenças. Complementam sintetizando que o trabalho do gestor, fundamentalmente, é planejar, organizar e coordenar, enquanto que o trabalho do líder é inspirar e motivar.

Sarros (2002), em seu estudo, sem fazer tanta distinção dos papéis, argumenta que os gestores e líderes precisam questionar orientações burocráticas no trabalho e as relações gestor-empregado repensando suas orientações de valor e adaptando novos modelos que estimulam realização, aprendizagem e desenvolvimento pessoal da equipe.

\subsection{Gestão}


Para Kotter (1990), a gestão lida com complexidade, uma característica das grandes corporações surgidas no século XX. A gestão traz ordem e consistência para que haja, como resultado, qualidade e lucratividade nos produtos. Com ela, evita-se o caos que ameaça até mesmo a existência das empresas.

A gestão enfrenta o futuro com planejamento e orçamento, tratando de definir metas (curto-médio prazo), passos para atingi-las e alocando os recursos necessários para tais ações. Trabalha com organização e alocação de pessoal, no sentido de estruturar cargos, selecionar e treinar pessoas, comunicar o planejamento e monitorá-lo. A gestão controla e resolve problemas, monitorando resultados vs. metas e agindo em cima das anomalias (Kotter, 1990).

$\mathrm{Na}$ mesma linha de raciocínio, corroborando com o autor anterior, Pessoa e Neves (2009) mencionam o gestor como administrador, citando a administração como ato de gerir negócios através de planejamento, organização, direção, coordenação e controle.

Segundo Drucker (2008), a gestão é um alicerce de uma organização. Para ele, são funções da gestão definir objetivos e missões da empresa, cuidar da eficácia do colaborador e gerir os desvios.

Mintzberg (1997) trata o trabalho do gestor como o mais vital para a sociedade, tamanha a sua importância. Na sua concepção de trabalho de gestão, o autor traz, como habilidades gerenciais importantes: desenvolvimento de relacionamentos entre pares, negociação, motivação de subordinados, solução de conflitos, estabelecimento de redes de informação e de divulgação das mesmas, capacidade de tomada de decisão (mesmo em ambientes de abundante ambiguidade), e também capacidade de alocação de recursos.

Ainda segundo o autor, o gestor necessita manter a capacidade de aprender no ambiente de trabalho, e seu papel nas organizações é tão fundamental que é ele que determina se as empresas servirão a sociedade ou se vão simplesmente desperdiçar (no sentido de mal empregar) os talentos e recursos que utiliza.

Borges e Mendes (2014) enxergam complexidade no processo de gestão, dada a sua característica de abranger um conjunto de funções essenciais para alcançar os objetivos da empresa. Os autores entendem que, desta maneira, um gestor deve possuir um rol diverso de competências para que consiga executar bem seu papel, que envolve organizar, orientar e manter sua equipe de trabalho direcionada para os valores e objetivos institucionais. 
Para Custódio, Machado, Ferreira e Dusi (2013) os gestores lidam com a diversidade de situações da rotina organizacional em curtos períodos, sendo grande o fluxo de atividades no ambiente das empresas. Gestores também estão em constante contato com as pessoas, abrangendo público interno e externo, comunicando, negociando, planejando, programando e controlando. Para que o gestor esteja alinhado e consiga atender os objetivos organizacionais, é necessário que tenha várias habilidades. Os autores também concluem que não existe um perfil padrão adequado de gestão, sem considerar a organização, a cultura e o momento. Todos estes são fatores que influenciam na decisão de qual é o melhor perfil de gestor, e este variará de acordo com tais fatores.

Kirjavainen, Björklund, Eloranta, \& Laakso (2010) detectaram, em seu estudo uma forte importância do trabalho de gestor, através da influência do trabalho destes na motivação e no desenvolvimento do trabalho da equipe. Concluíram que uma forte orientação e comprometimento dos gestores geram motivação no desenvolvimento do trabalho dos colaboradores. Especificamente num ambiente em que o gerenciamento de tarefas é menor, os resultados da pesquisa indicam que a criação de uma atmosfera de confiança com metas, papéis e claras divisões de poder teve sua importância aumentada - ou seja, é neste ambiente em que esta tarefa de responsabilidade do gestor se mostrou mais essencial.

Ainda segundo os autores, foi concluído que o equilíbrio entre a liberdade e a gestão e a clareza dos papéis na organização são a grande questão para dar o devido suporte aos funcionários da equipe.

Existe concordância do fato de que o processo de gestão lida com planejamento (Custódio et al., 2013; Kotter, 1990; Pessoa e Neves, 2009) e com organização (Borges e Mendes, 2014; Kotter, 1990).

O gestor também foi visto, com frequência, como responsável por lidar com a complexidade dentro das organizações (Borges e Mendes, 2014; Custódio et al., 2013; Kotter, 1990).

Em termos de essencialidade ou importância da atividade, a gestão foi tida como extremamente importante, vital ou essencial para as empresas (Custódio et al., 2013; Drucker, 2008; Mintzberg, 1997).

Por fim, há citações relacionando a atividade do gestor como geradora de motivação dentro da equipe (Kirjavainen et al., 2010; Mintzberg, 1997). 


\subsection{Liderança}

Segundo Kotter (1990), a liderança lida com mudança. Pelo mundo dos negócios ter se tornado mais competitivo e volátil, grandes mudanças se fazem necessárias nas corporações, e elas sempre exigem liderança.

Em termos de futuro, a liderança trabalha com uma direção, estabelecendo uma visão (longo prazo), e as estratégias para implementar as mudanças necessárias para alcançá-las. Preocupa-se com o alinhamento de todos, sendo que é necessária comunicação de qualidade entre pares, superiores, equipe e até mesmo terceiros, e a garantia de que eles tenham compreendido a visão, caminhando na sua direção. A liderança motiva e inspira, mantendo o direcionamento determinado e atenta às necessidades, valores e emoções das pessoas (Kotter, 1990).

De acordo com Allio (2005), o líder tem os seguintes papéis: estabelecer e reforçar valores e propósitos, desenvolver visão e estratégia, construir a comunidade necessária para a estratégia e, por último, implementar e gerenciar mudanças para o crescimento e sobrevivência da organização.

Para Borges e Mendes (2014), a liderança tem grande importância nas organizações. O líder, através da sua influência, estabelece boas relações e interfere no comportamento do grupo. A liderança, ainda segundo os autores, é considerada um processo de influência sobre todos aqueles que trabalham em prol dos mesmos objetivos. Um líder trabalha nos objetivos organizacionais desde a confecção destes até a sua execução, e para exercer a influência necessária, é preciso ser detentor de um poder legítimo, a ser concedido pela autoridade formalmente responsável por isto dentro da empresa.

Divergindo um pouco, Ferreira, Neves e Caetano (2001) dizem que liderar significa existir um membro exercendo influência sobre outros, e não necessariamente é formal (pode ser também informal, ou emergente). Um líder formal é nomeado e ocupa uma posição específica na hierarquia da instituição, tendo todas as responsabilidades inerentes sobre um grupo. Um líder informal ou emergente não é nomeado, mas tem capacidade de influência tamanha que se destaca no grupo.

Para Ivan e Terra (2017), os líderes são considerados o diferencial competitivo das organizações, não somente administrando processos, mas também acompanhando as pessoas com consideração. Líderes são capazes de diagnosticar as oportunidades e as mudanças, avaliando o ambiente interno e externo no que se refere ao mercado, 
buscando alinhar as estratégias organizacionais e os resultados, e cuidando das pessoas e dos processos alinhados aos objetivos da empresa.

Para Kich, Pereira, Emmendoerfer, \& Santos (2008), em trabalho sobre a influência do líder no planejamento estratégico, foi visto que o principal papel do líder é de motivador, atuando na delegação das tarefas às equipes que apoiarão no planejamento estratégico da organização. Os autores enfatizam a importância da liderança, pois perceberam, em seu estudo, que quando ocorreu mudança da direção da organização, o planejamento se estagnou. Eles reforçam, em seu trabalho, a necessidade da parceria da liderança com os funcionários, influenciando e gerando comprometimento de toda a equipe.

Segundo Ferreira (2019), a liderança, que antes comandava, hoje delega, respeitando as características e valores individuais e designando desafios compatíveis com a realidade da organização. O líder do futuro permite ser humano, ou seja, vulnerável, e trabalha aceitando críticas e sugestões. Ele age gerando confiança nas pessoas, motiva e valoriza as qualidades que permitem o trabalho em equipe.

Para Santos e Sliwowska (2010), os líderes influenciam seus liderados através de motivação e empoderamento, sempre em busca dos resultados organizacionais desejados. Para as autoras, "o líder efetivo usa sua influência sobre os outros visando antingir os objetivos organizacionais" (Santos \& Sliwowska, 2010, p. 35). Foi verificado que dentre as características do líder, destacam-se a cooperação, a iniciativa, o controle emocional e a autoconfiança, e que o estilo de gestão de pessoas predominante no contexto estudado era o democrático. Ao final, concluiu-se que o papel do líder na empresa é de, acima de tudo, garantir a transformação do conhecimento dos funcionários em produtitvidade, e em transformar o capital humano em valor para o cliente, trazendo, com isso, mais retorno financeiro para a organização e contribuindo para o sucesso da companhia".

Wu, Tsui, e Kinicki (2010) perceberam, em estudo realizado sobre a influência da liderança no desempenho de um grupo, analisando especificamente a diferenciação da mesma, que uma liderança diferenciada dentro de grupos alterou a eficácia destes, verificando, assim que o nível de diferenciação da liderança afeta o desempenho do grupo, trazendo mais ou menos eficácia.

Grant, Gino e Hofmann (2011) exploram um estilo específico de liderança, a extrovertida, e verificam que há uma influência desta no desempenho da equipe, e que 
tal influência varia de acordo com a característica dos funcionários - uma equipe passiva tem seu desempenho catalisado por este tipo de liderança, enquanto este efeito se reverte quando os colaboradores são proativos.

Segundo Thamhain (2012), em estudo sobre o papel do líder em um ambiente específico, a maioria dos gerentes de projetos nos contextos complexos verificados vê seu papel como líder de uma equipe de profissionais por meio de um processo difuso que nem sempre pode ser descrito linearmente ou planejado com perfeição, e nem os resultados podem ser previstos com certeza. Desta forma, foi detectado que um certo grau de flexibilidade e agilidade gerencial, desde o planejamento até a execução do projeto, é necessário para adaptar-se às dinâmicas e mudanças inevitáveis em um ambiente de negócios. Os líderes de equipe eficazes são arquitetos sociais que entendem a interação de variáveis organizacionais e comportamentais e podem fomentar um clima de participação ativa, responsabilidade e orientação para resultados em toda a empresa e seus parceiros externos. Para que esta cadeia funcione, é requerida uma compreensão profunda da dinâmica do ambiente de negócios e de suas culturas, além de um gerenciamento de projetos sofisticado, e também habilidades de liderança.

Para Jing e Avery (2008), embora a definição de liderança seja controversa, muitos profissionais e acadêmicos argumentam que a liderança cria uma ligação essencial entre a eficácia organizacional e o desempenho das pessoas. Segundo os autores, muitos outros escritores afirmam que os comportamentos de liderança podem induzir ou encorajar os funcionários a trabalhar melhor para melhorar seu comprometimento e satisfação, o que acaba refletindo em melhoria no desempenho organizacional. Quanto à eficàcia de certos tipos de liderança, os autores concluem que não existe um paradigma de liderança único que seja o mais eficaz. Em oposição, é mencionado no trabalho que uma organização deve adotar o estilo de liderança adequado ao contexto no qual a liderança e os seguidores interagem.

A liderança atua diretamente na visão da empresa (Allio, 2005; Kotter, 1990), trabalhando nos objetivos num horizonte de longo prazo. O líder é tido como responsável por gerenciar as mudanças no ambiente organizacional (Allio, 2005; Ivan e Terra, 2017; Kotter, 1990), lidando com todos os desafios que estas mudanças trazem no cotidiano da empresa. 
Assim como ocorre na função de gestor, o líder também é tido como de grande importância, sendo considerado até mesmo diferencial competitivo (Borges e Mendes, 2014; Ivan e Terra, 2017).

Quanto à formalidade do papel do líder viu-se divergência - há a teoria da necessidade da formalização para que se exerça o papel (Borges e Mendes, 2014), e também a vertente de que uma pessoa pode ser líder dentro da organização sem ter a formalidade do cargo (Ferreira et al., 2001).

Líderes também são vistos como pessoas que influenciam outras dentro da empresa - exercem seu papel através desta influência (Borges e Mendes, 2014; Ferreira et al., 2001; Santos e Sliwowska, 2010). Quando se testou a influência do líder no desempenho da equipe, verificou-se a existência deste (Grant et al., 2011; Wu et al., 2010).

Corroborando com os últimos achados, a liderança também é vista como geradora de motivação nas pessoas (Kich et al., 2008; Jing e Avery, 2008; Kotter, 1990; Santos e Sliwowska, 2010), e tal papel é reforçado quando se vê que o líder exerce sua função acompanhando as pessoas, agindo com consideração e levando em conta necessidades, valores e emoções de todos (Ferreira, 2019; Ivan e Terra, 2017; Kotter, 1990). Em outras palavras, o líder é visto como uma figura atenta aos valores humanos.

\section{CONSIDERAÇÕES FINAIS}

Ao final da avaliação da literatura sobre o tema estudado, pôde-se concluir que a linha que separa os papéis de gestor e líder é tênue, o que leva, às vezes, a ter descrições bastante similares entre os papéis, como se fossem usados apenas sinônimos, numa tentativa de diferenciá-los.

De maneira geral, foram encontrados mais estudos relacionados à liderança e seu papel, embora a gestão tenha sido considerada, quando estudada, tão importante e essencial quanto. Percebeu-se uma lacuna quanto a estudos específicos sobre as funções do gestor, determinando claramente seus papéis e contrapondo pontos de vista já estabelecidos.

A lacuna se aprofunda quando relacionamos a gestão ao desempenho - ao passo que há estudos analisando a influência da liderança no desempenho, com pesquisas medindo o resultado de uma área ou instituição vinculado à liderança existente, a literatura é bem mais escassa quando se troca a variável por gestão. 
Sugere-se, portanto, o aprofundamento nos estudos relacionados à gestão, e questiona-se, por outro lado, se a liderança tem um papel mais importante no desempenho das equipes e nos seus resultados. Seria este o motivo da maior abundância nos estudos relacionando liderança e desempenho? Tem a gestão um papel menos importante no desempenho? Seria a liderança um papel mais decisivo no resultado, e havendo necessidade de escolha, seria mais inteligente buscar habilidades de líder, em detrimento daquelas de gestor? São lacunas que se recomenda pesquisa, a fim de obter as devidas respostas.

Especificamente na literatura nacional, recomenda-se o aprofundamento nos estudos que comparam as funções de líder e gestor, como forma de disponibilizar aos interessados conhecimento teórico específico dos papéis.

Este artigo mostra-se importante para o ambiente organizacional por conseguir clarear para os gestores, formalmente responsáveis por equipes, os conceitos de gestor e líder, seus papéis e resultados esperados, para que eles os busquem, trabalhando rumo aos objetivos da empresa, e levem junto a sua equipe de trabalho. Entende-se que o papel do líder e do gestor são complementares, e que estando cientes das especificidades de cada um, é mais fácil exercê-los e caminhar em busca do melhor desempenho possível, considerando sempre o tipo de empresa, a cultura e o contexto organizacional.

Em suma, concluímos a existência específica e distinta do papel do gestor e do líder, e que eles podem ser complementares. Podemos definir o gestor como aquele responsável pelo planejamento, organização, e por lidar com a complexidade dentro das organizações. Já o líder é aquele que influencia outras pessoas dentro da empresa, trabalha em prol da visão da organização, gerencia mudanças e está atento às necessidades humanas. Ambos os papéis são extremamente importantes dentro da empresa, e possuem a capacidade de motivar pessoas.

Avaliando especificamente a liderança, a conclusão é que esta é um conceito totalmente à parte da gestão, embora a literatura sempre coloca o líder na posição do gestor. Mesmo em trabalhos em que os conceitos tentam ser apresentados à parte, em algum momento há a tangência, pois, o líder é colocado como responsável por papéis que representam funções precípuas do gestor. Entende-se que um líder, pelo papel que representa, é escolhido pelos liderados, e não por uma posição formal. Não há, necessariamente, relação hierárquica entre líder e liderados (um gestor pode ser líder, mas não necessariamente o é). Ainda considerando o que um líder representa, conclui-se 
que aqueles que o seguem não o fazem por outro motivo que não seja seus próprios interesses.

Dada esta ideia, o artigo finaliza cumprindo seu objetivo, conceituando a liderança e diferenciando-a do conceito de gestão, uma vez que cada um tem seu papel não obstante a importância de ambos.

\section{REFERÊNCIAS}

ADAIR, John. Liderança para o sucesso. São Paulo: Nobel, 1992.

ALLIO, Robert J. Leadership development: teaching versus learning. Management Decision, p. 1071-1077, ago. 2005.

BORGES, Flávio; MENDES, João Fernando de Sousa. Competências do gestor e do líder: estudo de caso. Lusíada. Economia \& Empresa, p. 89-120, jan. 2015.

DE MONTREUIL CARMONA, Linda Jessica; DE JESUS SILVA, Thiago Bruno; GOMES, Giancarlo. CULTURA ORGANIZACIONAL, INOVAÇÃO E DESEMPENHO EM ESCRITÓRIOS DE CONTABILIDADE BRASILEIROS. Contabilidade Vista \& Revista, v. 29, n. 3, p. 121-145, set. 2018.

CUSTÓDIO, Júlio César Dias et al. O trabalho, os papéis e as competências do gerente: reflexões à luz do modelo de gestão de Henry Mintzberg. Anais do X Simpósio de Excelência em Gestão e Tecnologia, Rio de Janeiro, RJ, Brasil, 2013.

DRUCKER, Peter F. O essencial de Drucker: Uma selecção das melhores teorias do pai da Gestão. 2008.

FERREIRA, J. M. Carvalho; NEVES, José; CAETANO, Antônio. Manual de Psicossociologia das Organizações. Lisboa: Escolar Editora, 2001.

GOMES, Luiz Flavio Autran Monteiro et al. Tomada de decisão gerencial: enfoque multicritério. São Paulo: Atlas, 2006.

GRANT, Adam M.; GINO, Francesca; HOFMANN, David A. Reversing the extraverted leadership advantage: The role of employee proactivity. Academy of Management Journal, v. 54, n. 3, p. 528-550, jun. 2011.

IVAN, Michele Vilela; TERRA, Leonardo Augusto Amaral. A influência da liderança na dinâmica organizacional. Caderno Profissional de Administração da UNIMEP, v. 7, n. 1, p. 137-159, 2017.

JING, Fenwick Feng; AVERY, Gayle C. Missing links in understanding the relationship between leadership and organizational performance. International Business \& Economics Research Journal (IBER), v. 7, n. 5, p. 67-78, mai. 2008. 
KICH, Juliane Ines Francesco et al. A influência do líder na condução do processo de implementação do planejamento estratégico. Ciencias da Administração, v. 10, n. 21, p. 122-146, 2008.

KIRJAVAINEN, Senni et al. The impact of leadership, management and power in an international knowledge-intensive organization. Cadernos EBAPE. BR, v. 8, n. 2, p. 339-352, jun. 2010.

KOTTER, J. P. What leaders really do Harvard Business Review on Leadership. Boston, MA: Harvard Business School, 1990.

MINTZBERG, Henrv. The manager's job: folklore and fact. Leadership: Understanding the dynamics of power and influence in organizations, p. 35-53, 1997.

PEREIRA, Alonso Luiz. A liderança como um fator de diferencial competitivo. Negócios em Projeção, v. 5, n. 1, 2014.

PESSOA, Raimundo Wellington Araújo; NEVES, João Adamor Dias. O perfil do gestor de clínicas médicas de Fortaleza. Revista de Administração, v. 7, n. 2, p. 96$116,2009$.

REGO, Arménio; CUNHA, M. P. A Essência da Liderança: Mudança. Resultados. Integridade: Teoria, Prática, Aplicações e Exercícios de auto-avaliação, p. 77-129, 2007.

ROTHMANN, Ian. Fundamentos de psicologia organizacional e do trabalho. Elsevier Brasil, 2017.

SANTOS, Fabianna; SLIWOWSKA, Aleksandra. Liderança estratégica - O sucesso das corporações alcançado através da liderança. Rio de Janeiro, 2010.

SARROS, James C. et al. Work alienation and organizational leadership. British Journal of Management, v. 13, n. 4, p. 285-304, 2002.

SHARMA, Manoj Kumar; JAIN, Shilpa. Leadership management: Principles, models and theories. Global Journal of Management and Business Studies, v. 3, n. 3, p. 309318, 2013.

THAMHAIN, Hans J. The changing role of team leadership in multinational project environments. Journal of Business and Projects, v. 3, n. 2, 2012.

WU, Joshua B.; TSUI, Anne S.; KINICKI, Angelo J. Consequences of differentiated leadership in groups. Academy of Management Journal, v. 53, n. 1, p. 90-106, 2010. 